\title{
TRABALHO: DIMENSÕES, SIGNIFICADOS E AMPLIAÇÃO DO CONCEITO
}

\author{
EL TRABAJO: DIMENSIONES, SENTIDO Y CONCEPTO DE EXPANSIÓN
}

WORK: DIMENSIONS, MEANINGS AND EXTENSION OF THE CONCEPT

\author{
Viviane Nascimento SILVA ${ }^{1}$ \\ Gilmar Ribeiro dos SANTOS ${ }^{2}$ \\ Sarah Jane Alves DURÃES ${ }^{3}$
}

RESUMO: Este artigo objetiva a realização de reflexões teóricas em torno do significado e a função do trabalho na sociedade. Uma visita aos clássicos, sobretudo Emile Durkheim e Karl Marx, permite problematizar as conotações assumidas pelo trabalho, perpassando uma trajetória histórica do trabalho até apontar algumas das contradições do modo de produção capitalista. Ao elucidar aspectos da reestruturação produtiva traz à tona possibilidades de debate acerca do processo de desconstrução e ampliação do próprio conceito de trabalho. A necessidade de refletir sobre o trabalho é fundamental para compreender as modificações e contradições assumidas enquanto categoria teórica e experiência prática no decorrer da história da humanidade. Se a análise decorrer dos princípios relativos aos sistemas de produção e reprodução da sociedade, certamente será possível perceber com maior clareza os motivos que conduziram e conduzem às recorrentes transformações no mundo do trabalho. As condições necessárias para exercer o trabalho ou demandadas a partir da sua realização também se modificam de acordo com o contexto econômico, histórico, político, social e cultural em que vivem os homens em sociedade.

PALAVRAS-CHAVE: Trabalho. Sociedade capitalista. Restruturação produtiva.

RESUMEN: Este artículo tiene como objetivo la realización de reflexiones teóricas sobre el significado y la función del trabajo en la sociedad. Una visita a los clásicos, especialmente Emile Durkheim y Karl Marx, permite analizar las connotaciones que asume el trabajo, pasando por una trayectoria histórica de trabajo para señalar algunas de las contradicciones del modo de producción capitalista. Para dilucidar los aspectos del proceso de reestructuración trae nuevas posibilidades para el debate sobre

1 Doutoranda e Mestre em Desenvolvimento Social pela Universidade Estadual de Montes Claros / Unimontes - MG. Especialista em Sociologia e Política e Bacharel em Ciências Sociais pela mesma universidade. Professora de Sociologia do Trabalho no Instituto Federal da Bahia - IFBA. E-mail: vnascimentosilva@yahoo.com.br

${ }^{2}$ Doutorado em Educação: História, Política, Sociedade pela Pontifícia Universidade Católica de São Paulo (2003). Atualmente é professor adjunto da Universidade Estadual de Montes Claros. E-mail: gilrds@uol.com.br

${ }^{3}$ Doutor em Educação: História, Política, Sociedade pela Pontifícia Universidade Católica de São Paulo (2002) e realizou estância pós-doutoral na Universidad de Barcelona (2006). Foi pesquisadora visitante na Universidad Autònoma de Barcelona, através de bolsa de pesquisa da Fundación Carolina/Espanha, em 2009. É professora do Departamento de Educação e do Programa de Pós-Graduação em Desenvolvimento Social da Universidade Estadual de Montes Claros. E-mail: sj-duraes@uol.com.br 
el proceso de deconstrucción y la extensión del concepto de trabajo. La necesidad de reflexionar sobre el trabajo es clave para entender los cambios y contradicciones asumidas como categoría teórica y experiencia práctica en el curso de la historia humana. Si el análisis sobre los principios para la producción y reproducción de los sistemas de la sociedad sin duda será posible ver más claramente las razones que llevaron y llevar a cambios recurrentes en el mundo laboral. Las condiciones necesarias para realizar el trabajo o exigieron a su realización también cambiar según el contexto económico, el medio ambiente histórico, político, social y cultural en el que viven los hombres en la sociedad.

PALAVRAS CLAVE: Trabajar. Sociedad capitalista. Reconversión productiva.

ABSTRACT: This article aims at the realization of theoretical reflections about the meaning and function of work in society. A visit to the classics, especially Emile Durkheim and Karl Marx, allows us to problematize the connotations of work, passing through a historical trajectory of the work until pointing out some of the contradictions of the capitalist mode of production. In elucidating aspects of productive restructuring, there are possibilities for debate about the process of deconstruction and expansion of the concept of work itself. The need to reflect on the work is fundamental to understand the modifications and contradictions assumed as a theoretical category and practical experience in the course of the history of humanity. If the analysis follows from the principles of society's production and reproduction systems, it will certainly be possible to perceive more clearly the motives which led to the recurring changes in the world of work. The conditions necessary to carry on the work or demanded from its realization also change according to the economic, historical, political, social and cultural context in which men live in society.

KEYWORDS: Work. Capitalist Society. Productive restructuring

\section{Introdução}

A necessidade de refletir sobre o trabalho é fundamental para compreender as modificações e contradições assumidas enquanto categoria teórica e experiência prática no decorrer da história da humanidade. Se a análise decorrer dos princípios relativos aos sistemas de produção e reprodução da sociedade, certamente será possível perceber com maior clareza os motivos que conduziram e conduzem às recorrentes transformações no mundo do trabalho. As condições necessárias para exercer o trabalho ou demandadas a partir da sua realização também se modificam de acordo com o contexto econômico, histórico, político, social e cultural em que vivem os homens em sociedade.

Este artigo tem como objetivo suscitar algumas reflexões no sentido de perceber teoricamente o significado e a função do trabalho na sociedade. A contribuição teórica para esta análise parte da teoria sociológica clássica, sobretudo de Emile Durkheim e 
Karl Marx e pretende alcançar algumas das abordagens contemporâneas no campo das Ciências Sociais que lidam com a reconfiguração do trabalho enquanto categoria teórica. Diante de uma trajetória histórica das mudanças em relação ao trabalho, é possível compreender as contradições do modo de produção capitalista diante de uma sociedade globalizada.

Primeiramente, cabe-nos apontar uma noção básica do que significa trabalho e refletir sobre a função que exerce na sociedade. Trabalho no sentido ontológico tem a ver com a interação que o homem estabelece com a natureza. Trata-se de uma atividade do gênero humano que é ao mesmo tempo objetivadora, social e consciente. Pode ser entendido como transformador ou produtor na sua essência. O trabalho com caráter transformador diz respeito à da capacidade do homem em utilizar os recursos disponíveis na natureza, para assim transformá-los visando a obtenção de bens necessários à sua sobrevivência. Já o trabalho visto como produtor trata-se da produção e reprodução de bens, serviços e relações oriundas desta transformação. Ainda é possível analisar o trabalho em termos de relação e utilidade. No primeiro caso, observam-se as relações produzidas, contatos estabelecidos e troca de experiências, possibilitados por meio do trabalho. Numa segunda perspectiva, o trabalho pode ser analisado a partir dos valores que adquire quanto a sua utilidade para o grupo social (MARX, 1932).

No decorrer da evolução, a humanidade foi aperfeiçoando este processo de transformação, produção e reprodução inerentes ao trabalho para atender às suas necessidades. A otimização dos recursos, o constante melhoramento das técnicas, a forma de produzir, foram assumindo condições variadas de acordo com a época, o lugar e o conjunto de valores e princípios sociais seguidos.

\section{A Divisão do Trabalho Social e Divisão Social do Trabalho}

A diferenciação entre a divisão do trabalho social e a divisão social do trabalho é oportuna para localizar os princípios que as definem e evitar confusões nas análises em relação ao trabalho enquanto categoria central de estudo.

O primeiro termo diz respeito a uma reflexão originariamente produzida por Émile Durkheim (1999), que trata das formas de estrutura social. Ele trata a ideia de função fazendo analogias entre um organismo vivo e a organização social. Assim, questiona qual a finalidade da divisão do trabalho para a sociedade, o que isso 
representa para manter certo equilíbrio de funcionamento da estrutura social. Suas reflexões apontam e identificam que além do caráter produtivo, a função que o trabalho exerce possui uma dimensão moral que une os indivíduos numa relação de interdependência.

As análises de Durkheim dedicam-se a compreender como as instituições, por exemplo, a família, o estado, a religião e o trabalho se organizam na estrutura social e qual o papel que cada uma representa para garantir a ordem da sociedade por meio dos princípios morais que transmite aos indivíduos. Assim se configura a divisão do trabalho social desempenhado pelas instituições que segundo ele, são responsáveis por dotar os indivíduos dos princípios morais necessários ao equilíbrio e ordenamento social. Desta forma, o trabalho se encaixa como uma das esferas da vida do indivíduo, cuja função vai além das características produtivas e perpassa pør uma dimensão moral do que ele chama de solidariedade ${ }^{4}$ (DURKHEIM, 1999).

O segundo termo de que trata este tópico refere-se à própria divisão social do trabalho, que consiste em assumir o trabalho enquanto categoria central de análise e refletir sobre as contradições internas e inerentes às formas de organização e divisão social. Aqui cabe questionar quais partes do processo de trabalho cada indivíduo se ocupa de realizar? Que complexidades existem? Em que condições o trabalho se desenvolve?

Neste campo de análise, o trabalho compreendido na sua forma clássica possui centralidade na estrutura social, sobretudo, porque constitui uma esfera importante de convívio, compartilhamento de regras, princípios morais, o que contribui para a coesão social.

\section{A divisão social do trabalho: reflexões sobre o trabalho e sua trajetória histórica}

A trajetória histórica do trabalho pode ser lida de diferentes maneiras, observando-se aspectos da evolução humana, ocupação do espaço por diferentes grupos humanos, relações de poder, elementos de ordem econômica, política, cultural, entre

\footnotetext{
${ }^{4}$ Durkheim faz uma distinção entre solidariedade mecânica e solidariedade orgânica. A primeira refere-se à forma de organização social, inclusive do trabalho, atribuída a sistemas naturais, simples e primitivos em que a natureza das funções exercidas dos indivíduos é dada quase que naturalmente. O segundo tipo de solidariedade, segundo ele, corresponde às formas de organização de sociedades complexas que tendem à especialização das funções, exigindo assim que cada indivíduo ou instituição estabeleça certo grau de solidariedade e dependência para que a organização social se mantenha ordenada.
} 
outros. Num debate mais aprofundado vamos encontrar termos como Divisão natural do trabalho, Divisão social do trabalho e Divisão do trabalho social, todos eles indicando perspectivas de análise vinculadas a períodos distintos, autores e correntes teóricas diversas que de alguma forma contribuíram para a discussão. Nesse sentido, as abordagens que se seguem possuem a intenção de problematizar estes conceitos e seu poder explicativo na tentativa de melhor compreender a noção de trabalho.

O homem pré-histórico é visto como um nômade. Seu trabalho se caracterizava basicamente pela coleta de bens da natureza que serviam à sua sobrevivência e a do grupo social. Numa visão essencialista, a divisão do trabalho ocorria de maneira natural de acordo com o sexo e a idade. Homens, mulheres e crianças assumiam naturalmente a sua função na divisão de tarefas.

O aprimoramento de algumas habilidades contribuiu para que estes grupos humanos se fixassem em determinados territórios, desenvolvendo assim a domesticação, técnicas de cultivo, pastoreio e artesanato que modificaram a configuração da forma de realizar o trabalho. Aqui a divisão de tarefas ainda que ocorra de acordo com o sexo e a idade, passa a exigir algum tipo de especialização, seja com a adoção de novas técnicas, seja com a introdução de metais, por exemplo, para a fabricação das ferramentas de trabalho.

Tais condições serão favoráveis ao surgimento da propriedade privada e, por conseguinte, a desigualdade social entre os homens, intensificando a existência de muitos conflitos 5 . E num salto histórico, a antiguidade fica marcada com o trabalho escravo evidenciando uma crescente desigualdade humana, numa situação em que o escravo se torna a ferramenta viva de realização do trabalho. A economia baseada neste tipo de mão-de-obra acentua as relações de desigualdade social num sistema de produção em que as relações vão além da esfera econômica e perpassam também as dimensões sociais, culturais, políticas, religiosas e familiares.

No modo de produção feudal, o trabalho servil vincula diretamente o trabalhador ao seu senhor, por meio de uma dependência e subordinação hereditária, traduzida em tributos devidos em troca do lugar e condições de sobrevivência. A própria organização política e social de poder descentralizado e economia amonetária baseada na agricultura

${ }^{5}$ Embora as discussões acerca das origens da propriedade privada e da desigualdade social mereçam destaque para a compreensão das mudanças do trabalho e no trabalho, neste momento não faremos menção deste tema. Noutro contexto, este debate será realizado de maneira devida. 
de subsistência reforçavam as condições de realização do trabalho neste período histórico.

A palavra trabalho origina-se do Latim tripalium, que consiste num instrumento feito de três paus aguçados, algumas vezes com ponta de ferro, que era usado por agricultores para bater, por exemplo, o trigo, espigas de milho, o linho, e rasgá-los e desfiá-los. Este tipo de trabalho serviu para criar a noção do trabalho associada ao sofrimento, o que permanece até o Séc. XV. Após essa época, o sentido do termo passa a ser o de laborar, obrar (ALBORNOZ, 2005).

Desde o Séc. XII, com o surgimento da burguesia, com o renascimento da vida urbana e comercial na Europa, o trabalho adquire uma dimensão corporativa, e seu exercício está diretamente ligado a associações de artesãos, mercadores e profissionais, com regulamentos específicos que autorizam a realização das atividades laborais.

Nesse sentido, a manufatura enquanto mecanismo de produção indica e se baseia numa divisão do trabalho, na medida em que operários se encontram no espaço da fábrica e executam diferentes ofícios que criam a mercadoria, juntando assim atividades artesanais que antes estavam separadas e divididas entre si.

A passagem da manufatura à indústria enquanto modo de produção é proporcionado por contradições e mudanças de ordem intelectual, política, econômica e social.

A Revolução Francesa, com seus ideais iluministas, e a Revolução Industrial com a introdução e/ou o aperfeiçoamento de técnicas de produção, marcam uma nova fase para a realização do trabalho. Trata-se do advento e ascensão do modo de produção capitalista, em que o trabalho passa a ser assalariado e torna-se uma das principais fontes de obtenção de lucro e acúmulo de capital. Aqui os conflitos se apresentam e se acentuam na dimensão dos interesses das classes envolvidas: burguesia e proletariado.

De um lado, a Revolução Francesa enquanto projeto político e intelectual corresponde ao fim do modo de produção feudal, ao passo em que os ideais iluministas de Liberdade, Igualdade e Fraternidade apontam para uma organização social centralizada, pautada por princípios científicos com influência positivista, que acaba enaltecendo, potencializando e retomando algumas das qualidades humanas como centro das reflexões.

Por outro lado, a Revolução Industrial representa a sistematização de um novo modelo econômico de produção que envolve o melhoramento das técnicas de produção 
à luz de princípios científicos; a organização social estabelecida em classes sociais distintas; a realização do trabalho visando o lucro e o aumento de capital.

O desenvolvimento da ciência moderna contribui para aprimorar o processo de produção e otimizar o tempo necessário à realização do trabalho. A introdução da máquina a vapor, o uso da eletricidade, os avanços nos meios de transporte, são exemplos de como o processo de produção, reprodução e circulação se modificou e se intensificou a partir daquele período.

Logo, se retomarmos,

$\mathrm{Na}$ manufatura, a divisão do trabalho exige o fato de que certos trabalhos necessários só podem ser realizados e, em consequência, nesse caso deve verificar-se, não somente uma distribuição, senão também uma efetiva divisão do trabalho entre grupos especialistas. (MARX, 1989, p.401)

No que diz respeito ao ambiente da fábrica,

[...] pelo contrário, se especializam precisamente as máquinas e o trabalho coletivo; ainda que as máquinas executem também operações sucessivas de um processo comum único, exigem igualmente a distribuição de grupos de trabalhadores [...]. Trata-se, portanto, de uma distribuição de trabalhadores entre máquinas especializadas, [e não] de uma divisão de trabalho entre trabalhadores especializados. [Na manufatura] se especializa a força de trabalho que emprega instrumentos particulares de trabalho: [na indústria] se especializam as máquinas, que são ajudadas por certos grupos de trabalhadores. (MARX, 1989, p.412)

No tocante à organização social, duas serão as classes que polarizam os conflitos e os interesses, a saber: a burguesia e o proletariado. A burguesia é constituída de proprietários de fábricas e indústrias espalhadas pela Europa da época, que controlam os meios de produção capitalista. O proletariado refere-se ao trabalhador que vende sua força de trabalho nestes espaços. E numa relação de exploração do primeiro para com o segundo, o modo de produção ser mantêm e se fortalece, acentuando cada vez mais as condições de desigualdade social.

\section{A organização do trabalho na sociedade capitalista e o processo de reestruturação produtiva}


A organização do trabalho na sociedade capitalista se orienta por alguns padrões que visam à acumulação de capital e a exploração da força de trabalho. A obra de Frederick Winslow Taylor foi fundamental para inspirar e orientar parte deste processo. A partir de observações realizadas, ele propõe a adoção de princípios de uma racionalidade científica no processo de produção, visando a otimização e a ampliação dos lucros. Objetivava assim, que os interesses contraditórios entre trabalhadores e patrões se encontrassem por meio da cooperação (TAYLOR, 1980). Outra importante contribuição foram as proposições apontadas por Henry Ford, que fornecem elementos da organização da linha de produção das fábricas. As práticas em torno destes princípios foram muito intensas em décadas anteriores do capitalismo, entretanto, ainda são presentes em muitos seguimentos produtivos e/ou conservam-se em muitos processos de trabalho atuais (FORD, 1964).

Para atender aos objetivos do capital, o processo de trabalho passa a ser organizado de maneira padronizada, densa e rígida, ao mesmo tempo em que os setores das fábricas são distribuídos de acordo com natureza do trabalho, estabelecendo assim uma distinção entre as habilidades e as características do trabalho e do trabalhador (ou até trabalhadora ${ }^{6}$ ) que o realiza. As relações de trabalho são controladas visando cada vez mais o aumento da produtividade e a diminuição dos custos da produção. E desta forma o trabalho foi e ainda é organizado para produzir mais e em menos tempo.

$\mathrm{Na}$ esfera da produção, o trabalho assume a condição de assalariado de acordo com as horas que o trabalhador cumpre para produzir a unidade básica do capitalismo: a mercadoria $^{7}$. Na esfera da circulação de bens, também podemos analisar o trabalho assumindo a condição de mercadoria se observamos os processos de valorização e desvalorização que ocorre em diferentes momentos e espaços em que o capitalismo opera.

As transformações de natureza socioeconômicas e socioculturais ocorridas nas últimas décadas desencadearam uma série de mudanças na estrutura da ordem social do capitalismo mundial. A sociedade densa, rígida, pesada, forte e sistêmica, representada

\footnotetext{
${ }^{6}$ Aqui surgem questões essencialistas e /ou de gênero que podem ser apontadas numa outra reflexão em torno da divisão do trabalho.

${ }^{7}$ A mercadoria é a unidade central do sistema capitalista que assume valor diante das circunstâncias de troca ou de uso. Na esfera de produção, inicia seu processo de valorização diante da relação entre matéria prima, quantidade de horas trabalhadas, taxações, processos de trabalho envolvidos. Ao sair da esfera da produção para a circulação, assume o valor de uso que é variável conforme as necessidades humanas vão sendo atribuídas. (MARX, 1989)
} 
pela figura do totalitarismo, do Fordismo e da burocracia, se transforma gradualmente numa estrutura nova, diferente, líquida, compulsiva, contínua e leve.

As categorias tradicionais como, por exemplo, a família, o estado, a classe social e o próprio trabalho, são reestruturados no que diz respeito à sua composição, valores, normas e procedimentos. O modelo de família patriarcal dá lugar a outras formas de representação da base familiar que evidenciam a busca por reconhecimento das diferenças e das relações de gênero em contraste com as condições de superioridade e inferioridade historicamente marcadas. O Estado que antes exercia sua função de forma centralizada, vivencia um processo de modernização baseado na lógica de um planejamento estratégico a fim de atingir os princípios da eficiência, eficácia e efetividade da sua ação. As condições e os limites que determinam o pertencimento a uma classe social específica são relativos e tênues, uma vez que a composição e o conceito de classe social passam por alterações e adaptam-se aos novos formatos da sociedade. O processo de produção no mundo do trabalho se modifica em meio a tais transformações, gerando novos significados no âmbito do tempo, nas categorias profissionais, na função e na divisão social do trabalho.

As bases estruturais da industrialização, marcadas pela enorme quantidade de produtos, com muito trabalhadores distribuídos conforme as funções específicas das etapas de produção, sofreram modificações decorrentes das inovações tecnológicas e passaram a exigir trabalhadores multifuncionais e flexíveis.

Segundo Harvey (1993), a acumulação flexível representou um modelo de produção capitalista em substituição ao modelo fordista, entre as décadas de 60 e 70 , que já não conseguia resolver os problemas emergentes no capitalismo. O sistema fordista entrou em declínio porque o mercado já não mais comportava a produção em massa, assim sendo, houve problemas no investimento de capital constante e de capital variável vinculado à produção massiva e em longo prazo.

A acumulação flexível, como vou chamá-la, é marcada por um confronto direto com a rigidez do fordismo. Ela se apoia na flexibilidade dos processos de trabalho, dos mercados de trabalho, dos produtos e padrões de consumo. Caracteriza-se pelo surgimento de setor de produção inteiramente novas maneiras de fornecimento de serviços financeiras, novos mercados e, sobretudo, taxas altamente intensificadas de inovação comercial, tecnológico organizacional. A acumulação flexível envolve rápidas mudanças dos padrões do desenvolvimento desigual, tanto entre setores como o entre regiões geográficas, criando, por exemplo, um vasto movimento no emprego chamado "setor de serviços", bem como conjuntos individuais, 
completamente novos em regiões até então subdesenvolvidas. (HARVEY, 1993, p. 140)

A nova forma produtiva que articula o desenvolvimento tecnológico e a desconcentração produtiva permite que o conhecimento dentro do processo de produção flexível torne-se essencial. O domínio de técnicas mais recentes, a apropriação dos mais novos produtos e a assimilação das mais recentes descobertas científicas, representa uma grande vantagem diante de um quadro competitivo, em um mundo onde as mudanças ocorrem de maneira rápida e os gastos e necessidades dependem de um sistema de produção mais flexível. Portanto, o conhecimento traduzido em capital intelectual é valorizado no processo de produção. A formação no sentido escolar ganha centralidade para atender às necessidades do mercado de trabalho, haja vista o destaque concedido à capacitação técnica e profissional. Dessa forma, os propósitos dos sistemas educacionais são redesenhados em virtude disso ${ }^{8}$.

De acordo com Harvey (1993), a acumulação flexível é, em suma, uma nova maneira encontrada pelo sistema capitalista de superar suas crises cíclicas e as contradições da concentração do capital. Trata-se, portanto, de um processo de acumulação flexível, em que a produção, o mercado e a força de trabalho também são flexíveis ${ }^{9}$.

A globalização econômica altera a estrutura da sociedade, em virtude das alterações provocadas nas fronteiras mundiais relativas à produção, montagem e comercialização de bens e serviços. Isso foi em grande parte facilitado devido aos avanços das tecnologias de informação, que permitem realizar diferentes tipos de comunicações instantaneamente em diversos lugares do mundo.

\begin{abstract}
A flexibilização dos processos de trabalho e de produção implica uma acentuada e generalizada potenciação da capacidade produtiva da forma de trabalho. As mesmas condições organizatórias e técnicas da produção flexibilizada permitem a dinamização quantitativa e qualitativa da força produtiva de trabalho. (IANNI, 1996)
\end{abstract}

A globalização do capital indica também a globalização das formas de trabalho, implicando novas formas sociais e novos significados de tempo e espaço para a execução do mesmo (IANNI, 1994). Isso impulsiona de um lado a otimização em

\footnotetext{
${ }^{8}$ Mais adiante, serão tratadas algumas das categorias teóricas referentes a esta elucidação.

${ }^{9} \mathrm{O}$ próprio conceito de trabalho passa por modificações à medida que se afasta da vinculação estreita com as atividades produtivas.
} 
relação aos custos e benefícios que o processo de trabalho garante ao capitalista e de outro a precarização estrutural do trabalho ${ }^{10}$.

Na maioria das vezes, as estratégias de gestão do capital serão favoráveis apenas aos capitalistas. Os cortes, o aperfeiçoamento técnico do processo de trabalho e os treinamentos visam à diminuição de custos e ao aumento de capital nas empresas. Nem sempre as medidas adotadas na esfera da produção, no ambiente da fábrica, beneficiam trabalhadores e capitalistas, salvo em situações como, por exemplo, os treinamentos e os intervalos de descansos que a empresa oferece ao trabalhador, e estas estratégias podem acabar lhes sendo favoráveis para além do trabalho.

O que Antunes (2010) considera como uma precarização estrutural do trabalho ocorre em função da flexibilização não apenas das formas de se executar o trabalho, mas também da flexibilização dos direitos trabalhistas que permitem ampliar os mecanismos de exploração e precarização do trabalho.

Para Ricardo Antunes (2002), estas transformações ocorridas no mundo do trabalho, provocam e explicam em certa medida a crescente desigualdade de oportunidades, trazendo à tona alguns dilemas: a necessidade constante de atualização, capacitação e adaptação para as exigências do trabalho; a precarização das condições de realização do trabalho; a incapacidade de organização dos trabalhadores em torno de melhorias, etc.

O mais brutal resultado dessas transformações é a expansão, sem precedentes na era moderna, do desemprego estrutural, que atinge o mundo em escala global. Pode-se dizer, de maneira sintética, que há uma processualidade contraditória que, de um lado, reduz o operariado industrial e fabril; de outro, aumenta o subproletariado, o trabalho precário e o assalariamento no setor de serviços. Incorpora o trabalho feminino e exclui os mais jovens e os mais velhos. Há, portanto, um processo de maior heterogeneização, fragmentação e complexificação da classe trabalhadora. (ANTUNES, 2002, p.47)

\section{Ampliação do conceito de trabalho para além das perspectivas clássicas}

Toda análise realizada até aqui pauta-se numa visão clássica em relação ao trabalho, cujos debates teóricos atribuem centralidade à esta categoria sociológica, enaltecendo a sua importância para a organização social e para a sobrevivência da vida humana. A organização da sociedade capitalista industrial pauta-se na tensão entre

${ }^{10} \mathrm{O}$ termo precarização é utilizado aqui para contextualizar o processo de desvalorização da força de trabalho. Noutro momento, merece ser devidamente citado e discutido. 
capital e trabalho, que permeia inclusive outras dimensões e esferas da vida, como, por exemplo, a família, o estado, a religião, etc.

A realidade social é dinâmica, e as mudanças ocorridas nas últimas décadas apontam algumas dificuldades de análise no âmbito das Ciências Sociais, tanto nos aspectos metodológicos, quanto teóricos e conceituais. As categorias sociológicas estabelecidas classicamente dizem respeito à contextos, épocas, lugares e situações específicas, diferentes inclusive de muitas situações contemporâneas. Logo, o que parecia enraizado e claramente definido, se confunde e assume novas conotações na atualidade, provocando uma crise de paradigmas. Diante da mudança da realidade social, síntese do objeto de estudo das Ciências Sociais, nota-se muitos esforços no sentido de mudar e adaptar também as formas de se estudar a realidade, de compreender tais mudanças. Clauss Offe (1989) aponta aspectos relativos ao declínio do modelo da pesquisa social centrado no trabalho, ao perceber, de um lado, certo deslocamento e diminuição dos estudos de natureza sistêmica, preocupados apenas com questões da ordem da produção, e, de outro, o aumento de pesquisas focadas na vida cotidiana, nas investigações acerca do que determina a consciência social, identidade coletiva e ação social. Daí alguns conceitos passam pelo crivo das reconstruções de seus significados na tentativa de avaliar seu poder explicativo diante das atuais circunstâncias.

Neste sentido, muitos debates sociológicos se debruçam sobre a categoria trabalho sob diferentes óticas a fim de diagnosticar suas metamorfoses e as condições que assume. Algumas constatações em torno do tempo de trabalho, local, condições de assalariamento, papel do conhecimento, uso das tecnologias, dentre outras, servem de parâmetro para as discussões em torno de termos como o fim da categoria trabalho, declínio do trabalho, fim do assalariado, precarização do trabalho, desvalorização do trabalhador, ampliação do conceito de trabalho, etc. As mudanças ocorridas na sociedade capitalista provocam uma problematização em torno do conceito de trabalho, demonstrada assim em algumas perspectivas de análise, como a ampliação da noção de trabalho, e em alguns casos aparece substituído pelo termo ocupação.

Toledo (2010) destaca em seu estudo que o trabalho é “[...] uma forma de interacción entre hombres y entre estos com objetos materiales y simbólicos, que todo trabajo implica construcción e intercambio de significados. " (p. 111). Dessa forma, ele propõe ampliar a noção de trabalho para uma construção social da ocupação, a se dedicar aos significados que o trabalho pode assumir a depender da sociedade, das culturas, das identidades envolvidas. Ao constatar que o emprego na indústria diminui 
nas últimas décadas em virtude de diferentes serviços, oferecidos por micro e pequenas empresas; a existência de trabalhos denominados precários; a exigência de novas qualificações; a informalidade e a flexibilidade em várias das relações de trabalho, etc, o autor aponta a coexistência de duas modalidades de trabalho: tradicional e moderna.

A modalidade tradicional consiste na forma clássica de realização do trabalho descrita no decorrer deste artigo, com local delimitado, carga horária definida, condições de assalariamento, subordinação a chefias e supervisores, estabilidade características típicas da sociedade capitalista industrial.

A condição moderna de realização do trabalho é denominada por Toledo (2010) de "forma não clássica" ou "atípica”, e por isso torna-se mais pertinente, de acordo com ele, ampliar o termo para ocupação. Trata-se de adotar uma concepção voltada para a sociedade pós-industrial, que dê conta de explicar os fenômenos relacionados à extensão dos trabalhos não assalariados, informais, precários, vulneráveis, flexíveis, não estruturados, atípicos, etc.

Quadro 1: Comparativo entre a noção de trabalho clássico e trabalho não clássico

\section{Trabalho clássico}

- Preocupação com salário, número de empregados, relação entre atores do trabalho (operários, supervisores, chefes);

-Preocupação com o controle dos processos de trabalho (tempo, método, movimentos, ferramentas, qualidade, qualificação, etc.)

-Regulação do trabalho, jornadas, conflitos, direitos e deveres;

-Subordinação a um patrão ou empresa;

- Clareza e delimitação entre tempo de trabalho e não trabalho;

-Produção fortemente fragmentada e modo de produção no chão de fábrica;

- Racionalização do processo produtivo visando a maximização de lucro.

\section{Trabalho não clássico}

-Processos de serviços em que o cliente participa da produção;

-Trabalhos desterritorializados;

-Produção de símbolos;

-Questões em torno da informalidade (idade, escolaridade, gênero, região, precariedade, exclusão, trabalho não decente);

-Posições demográficas podem implicar nas formas de consciência e de ação;

- Relações de compra e venda de trabalho envolve outros atores por meio da globalização;

-Valorização do conhecimento e das tecnologias nos processos de trabalho;

- Necessidade de perfis de trabalhadores polivalentes, multifuncionais.

Fonte: Elaboração própria (TOLEDO, 2010).

Diante disso, como analisar os indicadores de emprego, empregabilidade, desemprego e ocupação na sociedade atual? Como estudar a inserção e a fixação no mercado de trabalho? 
Se considerarmos as formas clássicas de trabalho, os trabalhadores que não estejam em condições de emprego e assalariamento encontram-se à margem do processo de produção. Pode haver menor correspondência entre o perfil dos trabalhadores e as condições de emprego e empregabilidade no processo de ocupação dos postos de trabalho existentes (POCHMANN, 2012).

Se considerarmos o trabalho numa visão mais ampla, considerando o conceito de construção social da ocupação, ainda que nem todos os trabalhadores consigam ocupar postos de trabalhos específicos, com condições de assalariamento, emprego com carteira assinada, eles ainda podem estar inseridos no mercado de trabalho flexível com ocupações diversas. Existem diferentes possibilidades de atuação deste trabalhador num novo cenário de realização do trabalho.

Esta interpretação é um tanto dúbia e perigosa na medida em que pode gerar interpretações e constatações diversas e erroneamente empregadas. De um lado, designar a terminologia ocupação para categorias de outras atividades laborativas, pode significar o reconhecimento e a valorização das diferentes formas de realizar trabalho, de garantir sobrevivência, e das diferentes possibilidades de formas de vida que a humanidade pode desenvolver. Isso retira inclusive a centralidade da categoria trabalho na vida humana, tratando-a apenas como uma das outras dimensões cotidianas. Em alguns grupos e sociedades, este fenômeno já se apresenta de maneira acentuada, redirecionando o rol de importâncias na vida das pessoas.

Por outro lado, no entanto, este pensamento também pode disseminar e perpetuar ideias que afetam as condições de desenvolvimento da sociedade. Pode ocorrer que sirva para justificar e reforçar a existência de desigualdades sociais num cenário de competição e precarização do trabalho, sobretudo quando ocorre o processo de responsabilização do indivíduo no que diz respeito à obtenção das qualificações que permitem condições de se inserir e fixar no mercado de trabalho. Esta, longe de ser uma reflexão paranoica em relação ao capitalismo, pode ser encarada como uma estratégia de autorregeneração em tempos de crise do próprio sistema.

O que merece então ser cuidadosamente observado diz respeito às escolhas teóricas e metodológicas que são usadas para realizar a leitura da realidade social. Se tomarmos única e exclusivamente a perspectiva clássica em relação à categoria sociológica trabalho, teremos certamente consideráveis análises de ordem sistêmicas; apontamentos sobre os grandes indicadores em relação ao emprego e desemprego da população; constatações sobre as condições precárias de trabalho, falta de acesso a 
salário, emprego, outras condições inerentes ao trabalho. Entretanto, se ampliamos a noção de trabalho para a dimensão da ocupação, trazendo à tona novas interpretações, será possível e necessário avançar para além dos estudos sistêmicos, uma vez que eles não conseguem mais explicar a realidade do mundo do trabalho como ele o é agora. Outros parâmetros são necessários para, além de classificar, compreender as lógicas de ação existentes.

\section{Considerações Finais}

Diante das reflexões apresentadas, cabe considerar que o trabalho parte de um sentido ontológico para assumir a condição de categoria teórica de análise a partir da sua trajetória histórica.

A importância do trabalho para a organização da estrutura social contribui para determinar as formas de produção adotadas pela sociedade.

A organização do trabalho na sociedade capitalista carrega consigo uma complexidade que envolve processos produtivos visando a constante acumulação de capital.

Os avanços tecnológicos e as mudanças de natureza econômica levaram à reestruturação produtiva pela qual atravessou o modo de produção capitalista. Isso conduziu a distintas transformações no mundo do trabalho e trouxe à tona novas necessidades.

O trabalho entendido na sua forma clássica possui suas bases na sociedade capitalista industrial e carrega um conjunto de características que mudam ao longo do tempo. A sociedade pós-industrial provoca alterações na forma de realizar o trabalho, provocando uma problematização em torno do próprio conceito, exigindo assim a ampliação da noção de trabalho para a de ocupação. A depender de qual perspectiva se utilize para estudar o trabalho no campo das ciências sociais, temos ideias e discussões que ora se aproximam, ora divergem em torno das circunstâncias.

\section{Referências}

ALBORNOZ, Suzana. O que é trabalho. Coleção Primeiros Passos. Editora Brasiliense. São Paulo, 2005.

ANTUNES, Ricardo. Adeus ao trabalho? Ensaio sobre as metamorfoses e a centralidade do mundo do trabalho. 8. ed. São Paulo: Cortez Editora, 2002. 
BERNARDO, João. A produção de si mesmo. Educação em Revista. nº 10 Belo Horizonte, UFMG. 1989. p..3-17. Disponível em: <http://educa.fcc.org.br/pdf/edur/n09/n09a02.pdf>. Acesso em 20 jul. 2013.

BRAVERMAN, Harry. Trabalho e gerência. In: Trabalho e capital monopolista. 3. ed. Rio de Janeiro: Guanabara, 1987. P.47-134. (I Parte).

BRAVERMAN, Harry. Nota final sobre qualificação. In: Trabalho e capital monopolista. 3. ed. Rio de Janeiro: Guanabara, 1987. p.359-379

DURKHEIM, Emile. Métodos para determinar essa função. In: A divisão do trabalho social. São Paulo: Martins Fontes, 1999. p. 13-37.

DURKHEIM, Emile. A solidariedade devida à divisão do trabalho ou orgânica. In: A divisão do trabalho social. São Paulo: Martins Fontes, 1999. p. 85-109.

FORD, Henry. Minha vida e minha obra. Rio de Janeiro: Brand, s.d.

FERNANDES, Luís. Neoliberalismo e Reestruturação Capitalista. In: SADER, Emir, GENTILI, Pablo. Pó-Neoliberalismo - as políticas sociais e o estado democrático. Rio de Janeiro: Paz e Terra, 1995. PP.54-61

IANNI, O. Teorias da globalização. 3. ed. Rio de Janeiro: Civilização Brasileira, 1996. IANNI, Otávio. O Mundo do Trabalho. In: Revista Perspectiva. São Paulo, Fundação SEADE, Vol. 08, Nº 1, 1994.

MARX, Karl. Processo de trabalho e processo de produzir mais valia. In: O capital. Rio de Janeiro: Bertrand Brasil, 1989.p.201-223.

MARX, Karl. Divisão do trabalho e manufatura. In: O capital. Rio de Janeiro: Bertrand Brasil, 1989.p.386-.422.

POCHMANN, Márcio (2012). Classes do Trabalho em Mutação. Rio de Janeiro, Revan.

TAYLOR, Frederick. Princípios da racionalidade científica. 7.ed. São Paulo: Atlas,n 1980.

TOLEDO, Enrique de la Garza (2011). Hacia un concepto ampliado de trabajo: Del concepto clásico al no clásico In. El mundo del trabajo en América Latina. México, 2010 pp.111-140; Barcelona, Anthropos Editorial, 2011.157p

SANTOS, Milton. Por uma outra globalização - do pensamento único à consciência universal. São Pauto: Record, 2000.

\section{Como referenciar este artigo}

SILVA, Viviane Nascimento.; SANTOS, Gilmar Ribeiro.; DURÃES, Sarah Jane Alves. Trabalho: dimensões, significados e ampliação do conceito. Revista IberoAmericana de Estudos em Educação, Araraquara, v. 12, n. 2, p. 739-754, 2017. Disponível em: <http://dx.doi.org/10.21723/riaee.v12.n2.8356>. E-ISSN: 1982-5587.

Recebito em: 05/02/2016

Aprovação final em: 04/04/2017 